\title{
FRUCTOLYSIS AND RESPIRATION OF BUFFALO SPERMATOZOA
}

\author{
K. K. GANDHI AND S. R. ANAND \\ National Dairy Research Institute, Karnal, India
}

(Received 25th February 1975)

Studies of buffalo semen have so far been directed towards eliciting its basic chemical composition and preserving the spermatozoa in vitro. Very little is known about the metabolism of buffalo spermatozoa except that they can oxidize fructose (Sengupta et al., 1963; Sinha et al., 1966). The observations made by us on the fructolysis and respiration of buffalo spermatozoa are presented in this paper because of their intrinsic comparative interest.

Semen was collected from Murrah buffalo bulls by using an artificial vagina. Pooled samples from one or two bulls whose spermatozoa showed good initial motility were used. Sperm counts were carried out in duplicate with a haemocytometer and the proportions of live spermatozoa were determined from smears stained with nigrosin-eosin. Motility was scored arbitrarily from 5 for vigorously motile to 0 for immotile spermatozoa; under anaerobic conditions, the spermatozoa were examined in a sealed capillary tube. For dilution, suspension and washing of the spermatozoa, Krebs-Ringer phosphate buffer (145 mM-NaCl, $5.80 \mathrm{~mm}-\mathrm{KCl}, 1.46 \mathrm{~mm}-\mathrm{MgSO}_{4} .7 \mathrm{H}_{2} \mathrm{O}, 6$ mm-sodium phosphate) or Krebs-Ringer solution (145 mM-NaCl, $5.80 \mathrm{~mm}-\mathrm{KCl}, 1.46 \mathrm{~mm}$ $\mathrm{MgSO}_{4} .7 \mathrm{H}_{2} \mathrm{O}, 1.47 \mathrm{~mm}-\mathrm{KH}_{2} \mathrm{PO}_{4}$ ) were used. All incubations of spermatozoa were carried out in a single side-arm constant-volume Warburg apparatus at $37^{\circ} \mathrm{C}$ with a shaking rate of 100 strokes $/ \mathrm{min}$. In anaerobic experiments, $2 \mathrm{ml}$ whole semen (total sperm density, 1 to $1.5 \times 10^{9}$ cells) were placed in the main flask, $1 \mathrm{ml} \mathrm{Krebs-Ringer} \mathrm{phosphate} \mathrm{buffer} \mathrm{in} \mathrm{the} \mathrm{side-arm} \mathrm{and} \mathrm{a} \mathrm{small} \mathrm{piece} \mathrm{of}$ yellow phosphorus in the centre well. The flasks were fitted to the manometer and gassed with dry nitrogen for $3 \mathrm{~min}$ through the side-arm. After $15 \mathrm{~min}$ equilibration at $37^{\circ} \mathrm{C}$, the contents of the side-arm were poured into the main flask and mixed. The flasks were shaken and samples removed at 0-, 1-, 2- and 3-hr intervals for fructose and lactic acid estimations. In aerobic experiments, the experimental conditions were the same except that the centre well contained $0.2 \mathrm{ml}$ of $20 \% \mathrm{KOH}$ with $0.8 \mathrm{ml} \mathrm{Krebs-Ringer} \mathrm{phosphate} \mathrm{buffer} \mathrm{in} \mathrm{the} \mathrm{side-}$ arm. The manometers were filled with air. For respiration studies, the uptake of $\mathrm{O}_{2}$ by whole semen and the seminal plasma was observed at 30 -min intervals. For studies of washed spermatozoa, fresh semen was diluted $\times 4$ with KrebsRinger solution and centrifuged at $400 \mathrm{~g}$ in a clinical centrifuge. The seminal plasma was removed and the sperm pellet was washed once more in a similar fashion. The pellet was finally suspended in an appropriate volume of KrebsRinger solution for studies of washed spermatozoa. Fructose was estimated by the method of Mann (1948) and lactic acid was determined by the method of 
Barker \& Summerson (1941). The estimations on all the samples were run in duplicate. Semen was subjected to cold shock by the treatment of Mann \& Lutwak-Mann (1955).

Twenty-three samples of fresh buffalo semen analysed for lactic acid contained between 0.5 and $3.0 \mathrm{mg} / \mathrm{ml}(0.83 \pm 0.17$, S.E.). The value is high compared with those for other species (Mann, 1964). The anaerobic disappearance of fructose and formation of lactic acid was studied in eight different experiments; the data for four are plotted in Text-fig. I. The amount of lactic

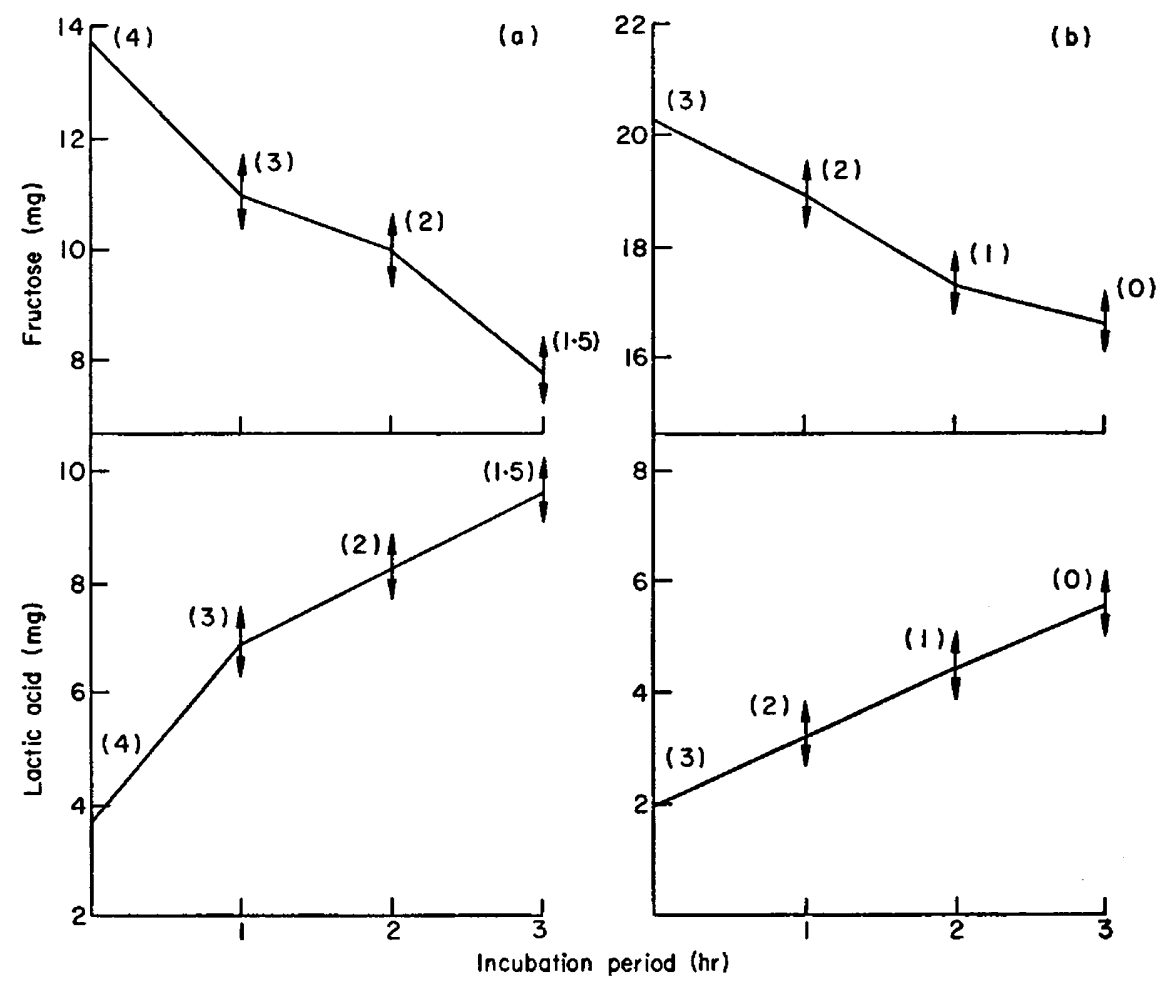

TExT-FIG. 1. Time relationship between fructose utilization and lactic acid production at $37^{\circ} \mathrm{C}$ by buffalo spermatozoa ( 1 to $1.5 \times 10^{9}$ cells) in whole semen under (a) anaerobic and (b) aerobic conditions. The vertical arrows indicate the range of four experiments and numbers in parentheses are motility ratings $(0$, immotile to 5 , very motile). For other details, see text.

acid accumulated in the eight experiments varied between 70 to $100 \%$ (mean $87 \%$ ) of the fructose utilized. The remaining $13 \%$ may be organic acids other than lactic acid which have been obtained under similar conditions in other species (Rothschild, 1964; Graves et al., 1966; Nevo et al., 1970). The fructolysis indices ( $\mathrm{mg}$ fructose utilized/hr by $10^{\circ}$ spermatozoa at $37^{\circ} \mathrm{C}$ ) for the $1 \mathrm{st}$, 2nd, and $3 \mathrm{rd}$ hr of incubation were $3.25 \pm 0.49$ (S.E.), $1.49 \pm 0.47$, and $0.9 \pm 0.9$ at an initial fructose concentration of $16.56 \pm 1.6 \mathrm{mg} / 3 \mathrm{ml}$. These values are slightly higher than those $(1 \cdot 4$ to $2 \cdot 0)$ reported for the fructolysis index of human, bull, 
and ram semen (Mann, 1964). Simultaneous observations on sperm motility showed that it fell during the period of incubation; after $3 \mathrm{hr}$ only a small percentage was still motile with about one-third of the initial motility. Aerobic utilization of fructose was lower than anaerobic utilization and less lactic acid accumulated (Text-fig. 1). The fructolysis indices calculated from the data of nine experiments gave a mean value of $1.53 \pm 0.55$ (S.E.), $1.12 \pm$ 0.92 , and $1.16 \pm 0.25$ for the 1st, $2 \mathrm{nd}$, and $3 \mathrm{rd} \mathrm{hr}$ of incubation. The mean initial fructose concentrations were $15 \cdot 75 \pm 3.0 \mathrm{mg} / 3 \mathrm{ml}$. Motility fell more rapidly than in anaerobic conditions and the spermatozoa were immotile after $3 \mathrm{hr}$ of incubation, indicating that buffalo spermatozoa are not able to make sufficient use of energy generated during aerobic metabolism to sustain their motility.

Table 1. Respiration $\left(\mu \mathrm{l} \mathrm{O}_{2}\right.$ uptake $/ 10^{8}$ spermatozoa) of whole semen and seminal plasma from buffalo bulls

\begin{tabular}{lcccc}
\hline $\begin{array}{c}\text { Time } \\
(\mathrm{hr})\end{array}$ & Motility & $\begin{array}{c}\% \\
\text { live sperm. }\end{array}$ & Whole semen & Seminal plasma \\
\hline 0 & $3 \cdot 0$ & 75 & $13 \cdot 30$ & $-\overline{80}$ \\
1 & 1.5 & 59 & $23 \cdot 0$ & 1.00 \\
2 & 0.5 & 51 & $29 \cdot 40$ & $1 \cdot 40$ \\
3 & 0.125 & 32 & & \\
\hline
\end{tabular}

Values represent the mean of nine experiments at a mean sperm concentration of $1.25 \times 10^{9}$.

The $\mathrm{O}_{2}$ uptake of buffalo semen is chiefly due to spermatozoa and there is very little contribution from the seminal plasma (Table 1). When rendered immotile by cold shock buffalo spermatozoa could not utilize $\mathrm{O}_{2}$. The values obtained are in agreement with those reported by Sengupta et al. (1963) for buffalo spermatozoa and also fall within the range reported for other species (Mann, 1964). The addition of phosphate ions $(20 \mathrm{~mm}$ final concentration) had no effect on the $\mathrm{O}_{2}$ uptake by buffalo spermatozoa and is not surprising because buffalo seminal plasma has high concentrations of inorganic ions (Sengupta et al., 1963). In washed buffalo spermatozoa, however, inorganic phosphate was required for maximum $\mathrm{O}_{2}$ uptake; $5 \mathrm{~mm}$ was the optimum concentration which enhanced $\mathrm{O}_{2}$ uptake and aerobic fructolysis. A twofold increase in $\mathrm{O}_{2}$ uptake and fructolysis index of buffalo spermatozoa was also seen when the $\mathrm{pH}$ of the suspending buffer was raised from 4.5 to 8.0 . The rates for aerobic fructolysis of washed spermatozoa were comparable to those observed for whole semen. In anaerobic experiments, the fructose content decreased after the 1st and 2 nd hr of incubation but a consistent increase was observed during the 3rd hr. Lactic acid values were far below those expected theoretically. Washed buffalo spermatozoa were able to utilize glucose and mannose to the same extent as fructose. Pyruvate and lactate were oxidized at a slower rate. The endogenous respiration was sustained at rates slightly lower than those with pyruvate as substrate (Text-fig. 2). 


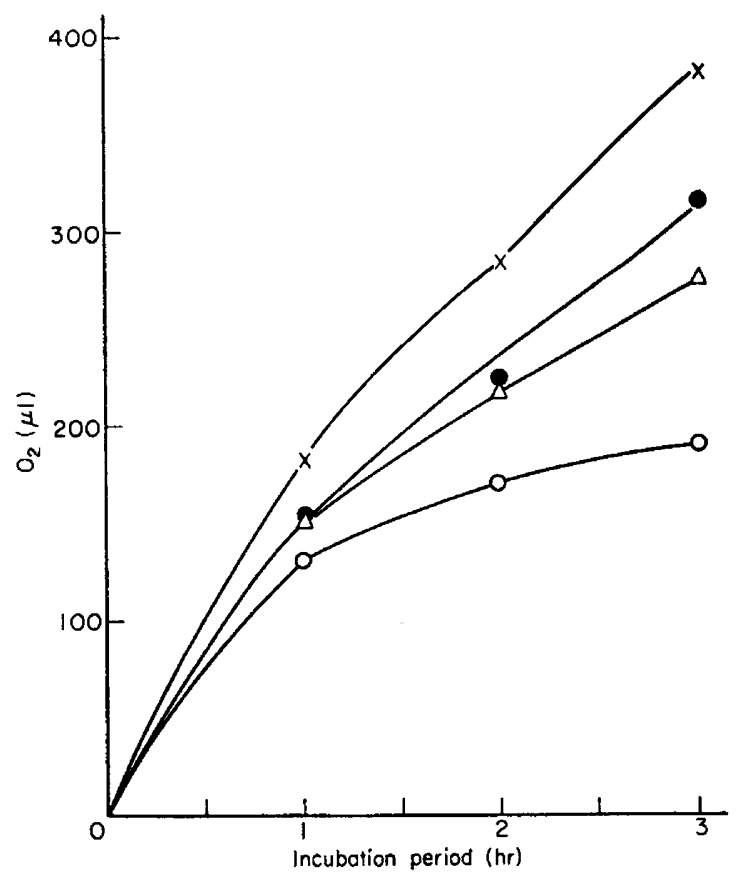

TExT-FIG. 2. Effect of exogenous substrates on the $\mathrm{O}_{2}$ uptake of washed buffalo spermatozoa. Spermatozoa $\left(1.2 \times 10^{9}\right.$ cells/flask) were suspended in Krebs-Ringer phosphate buffer containing fructose $(18 \mathrm{mg} / 3 \mathrm{ml})(x)$, pyruvate $(10 \mathrm{mg} / 3 \mathrm{ml})(0)$, lactate $(10 \mathrm{mg} / 3 \mathrm{ml})(0)$, or no substrate (endogenous) $(\Delta)$.

We should like to thank the Director, Dr D. Sundaresan, for his kind help and encouragement, the Indian Council of Agricultural Research for partial funding of this work and Mrs Bernie Humburg for help in preparation of the manuscript, which is N.D.R.I. Publication No. 74-74.

\section{REFERENCES}

BARKER, S.B. \& Summerson, W.H. (1941) The colorimetric determination of lactic acid in biological material. F. biol. Chem. 138, 535-554.

Graves, G.N., Lodge, J.R. \& Salisbury, G.V. (1966) Metabolic end products of anaerobic spermatozoan metabolism. Nature, Lond. 211, 308-309.

ManN, T. (1948) Fructose content and fructolysis in semen. Practical application in the evaluation of semen. F. agric. Sci., Camb. 38, 323-338.

Mann, T. (1964) The Biochemistry of Semen and of the Male Reproductive Tract. Methuen, London.

MANN, T. \& LuTwAK-MANN, C. (1955) Biological changes underlying the phenomenon of cold shock in spermatozoa. Archs Sci. Biol. 39, 578-588.

Nevo, A., Polge, C. \& Frederick, G. (1970) Aerobic and anaerobic metabolism of boar spermatozoa in relation to their motility. F. Reprod. Fert. 22, 109-118.

RothschisD, LORD (1964) Anaerobic fructolysis. Lactic acid and heat production of bull spermatozoa. Proc. R. Soc. B, 159, 291.

Sengupta, B.P., MisRA, M.S. \& Roy, A. (1963) Climatic environmental and reproductive behaviour of buffaloes: effect of different season on various seminal attributes. Ind. F. Dairy Sci. 16, 150-165.

Sinha, R.G., Sengupta, B.P. \& Roy, A. (1966) Climatic environmental and reproductive behaviour of buffaloes: comparative study of oxygen uptake, aerobic fructolysis by Murrah (B. bubalis) and Hariana (B. indicus) spermatozoa during different seasons. Ind. F. Dairy Sci. 19, 18-24. 